\title{
A Study on Future Energy Consumption and Carbon Emissions of China's Transportation Sector
}

\author{
Hailin Wang1, Xi Yang1,2, Xunmin Ou1,2* \\ ${ }^{1}$ Institute of Energy, Environment and Economy, Tsinghua University, Beijing, China \\ ${ }^{2}$ China Automotive Energy Research Center, Tsinghua University, Beijing, China \\ Email: ouxm@tsinghua.edu.cn
}

Received 10 September 2014; revised 6 October 2014; accepted 2 November 2014

Copyright (C) 2014 by authors and Scientific Research Publishing Inc.

This work is licensed under the Creative Commons Attribution International License (CC BY). http://creativecommons.org/licenses/by/4.0/

c) (i) Open Access

\section{Abstract}

The actual energy consumption of China's transportation sector accounts for $10 \%-15 \%$ of the nation's total energy consumption. Experience from developed countries shows that on entering a phase of stable urbanization, transportation will account for around $30 \%$ of total energy consumption, close to levels seen in developed nations (nearly 40\%). Transportation in China is one of the sectors with the fastest growth in energy consumption. A literature review shows an obvious future growth in China's total energy usage within this sector, with a continuous increase from baseline until 2050. However, with strict policy the growth will drop a little by 2030, but will still be about 1.5 times higher than current levels (reported in 2010) in 2050. Therefore, China needs to further optimize traffic infrastructure, properly allocate resources, and improve transportation technology and energy efficiency. This will help realise infrastructural energy saving and facilitate China's low-carbon transportation sector development.

\section{Keywords}

Transportation Sector, Energy Consumption, Low Carbon, China

\section{The Transportation Sector Is a Major Source of Global Energy Consumption and Carbon Dioxide Emissions}

Globally, the transportation sector is a major source of energy consumption and carbon dioxide emissions. In 2011, for example, this sector accounted for $18 \%$ of primary energy consumption, and $20 \%$ of total $\mathrm{CO}_{2}$ emis-

\footnotetext{
"Corresponding author.
} 
sions [1]. Over the past 30 years, its annual growth rate (especially for oil consumption) reached over $2.6 \%$, far more than that of industrial, residential and other sectors. From a country perspective, emerging economies such as China, Southeast Asia and Latin America, have a much higher growth rate.

The energy consumption of the transportation sector varies by the development stage of each country. In Figure 1, the bubble size represents the final energy consumption by transportation sector in specified country in the main years. The percent of the vertical axis represents the proportion of final energy consumed by transportation sector in respective total domestic final energy consumption. In the USA, with a large territory and completed industrialization, the transportation industry is relatively mature and its energy consumption accounts for a larger share (nearly $40 \%$ ) of the total domestic energy consumption. Similarly, due to a smaller land area and a higher population density, Japan's final energy consumption in transportation sector accounts around a quarter of its total domestic energy consumption. Compared to these developed countries, China's per capita energy consumption by the transportation sector is far below the global average, due to its large population. However, along with the rapid industrialization and urbanization in recent years, the energy consumption by this sector has also increased.

\section{Rapid Growth in Energy Consumption and Carbon Dioxide Emissions of China's Transportation Sector}

According to statistics from the Institute of Energy Economics (IEE) of Japan, the final energy consumption by China's transportation sector increased from 24.1 Mtoe (million tons of oil equivalent) in 1980 to 182 Mtoe in 2010, with a $6.74 \%$ increasing rate annually. When compared to total final energy consumption, the proportion used by the transportation sector soared from $7.65 \%$ in 1980 to $13.86 \%$ in 2010 . However, this proportion in China is far lower than the current levels (in 2010) of some developed countries, such as $23.66 \%$ of Japan, $38.87 \%$ of the US and $30.49 \%$ of the global average [2].

The rapid growth of road and air transport has resulted in China's transportation sector mainly relying on oil as the main energy source (for instance, the proportion of oil consumption reached $96 \%$ in 2005). According to calculations by Wang Qingyi (2013) [3], the transportation sector consumed85.1 million tons of gasoline and 113 million tons of diesel in 2012. Gasoline was mainly consumed by road transportation, and 66\% of diesel was consumed in transportation industry in 2012, which is a significant increase compared to $27.5 \%$ in 2000 .

Figure 2 shows the total amount (bubble size) of final energy consumed by China's transportation sector, and its relative proportion to the total final energy consumption of the world's transportation sector [2]. The figure shows that the total final energy consumed by this sector in China is increasing at a fast rate. Following nearly 30 years of economic development, the proportion of the final energy consumed by China's transportation sector has increased from less than $2 \%$ to $7 \%$ of the global transportation sector total, attracting worldwide attention.

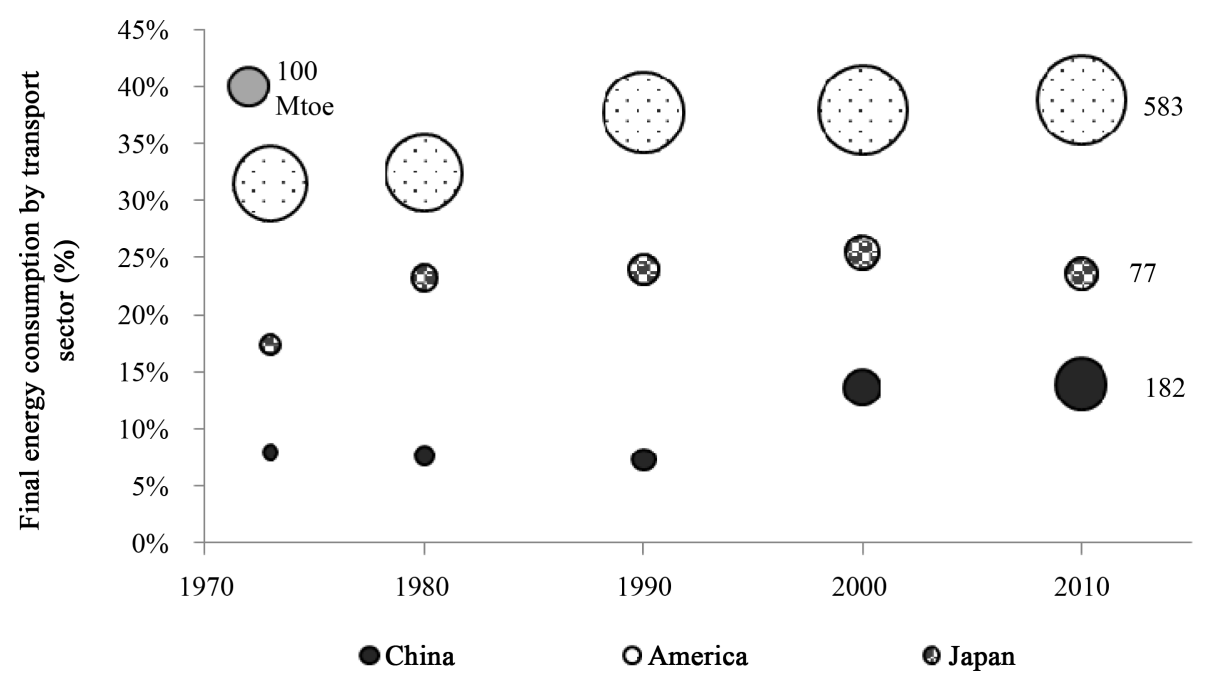

Figure 1. Proportion of final energy consumed by the transportation sector in relation to total domestic energy consumption by countries. 


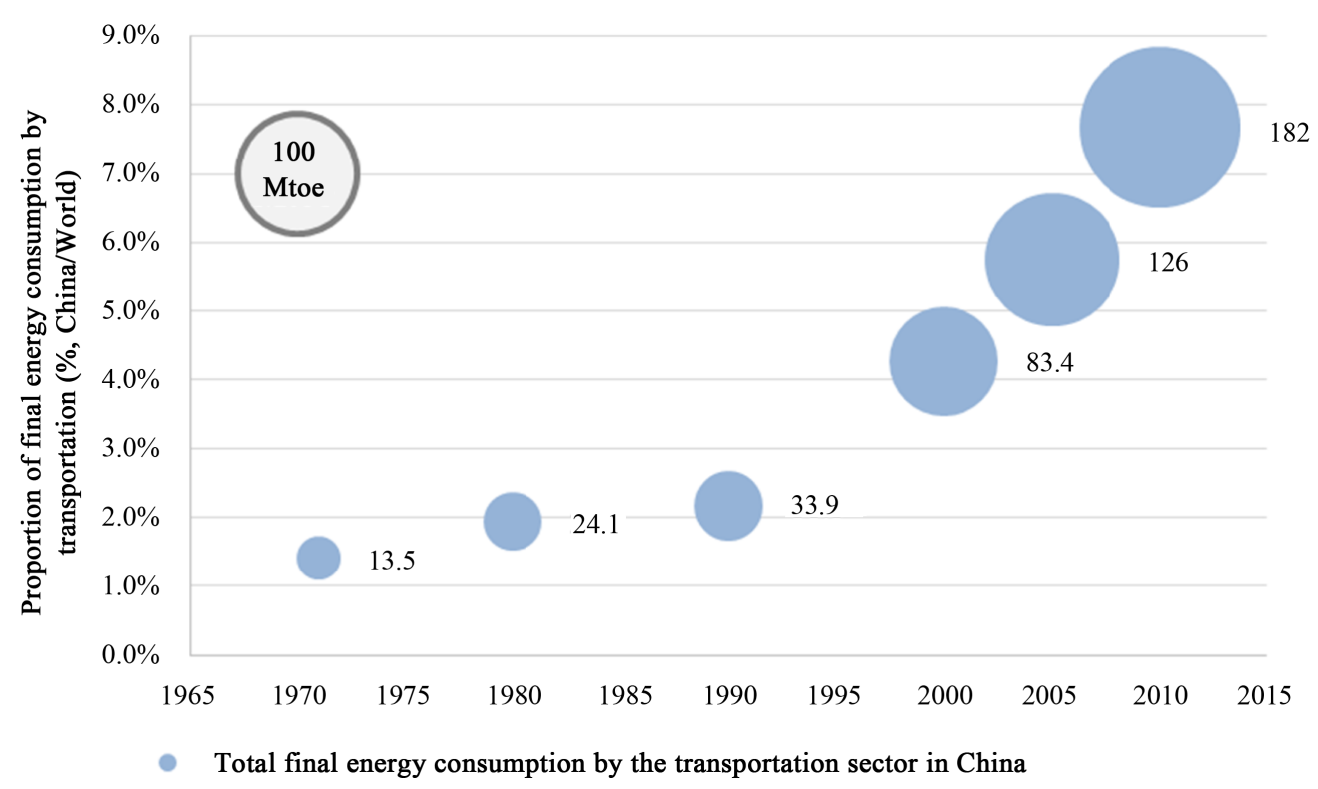

Figure 2. Total final energy consumption of China's transportation sector and its proportion in the world's transportation sector.

Over the next 10 to 20 years, China will continue its rapid progress of urbanization and industrialization, and its transportation sector will also experience a period of rapid growth. Thus, the key issue the country currently faces is ways to develop low-carbon, efficient transportation in a coordinated and orderly fashion.

According to the International Energy Agency’s (IEA) Energy Technology Perspectives, the energy consumption by transportation sector in China is likely to increase from 184 Mtoe in 2010 to 517 Mtoe in 2035, equivalent to $21.52 \%$ of the total final energy consumption at that time [4].

From a global perspective, the transportation industry accounted for about $22 \%$ of $\mathrm{CO}_{2}$ emission in 2010. In developed countries, the proportion of the USA was around 30.2\% and that of Europe was around 26.5\%. In contrast, China's proportion was about $7.0 \%$ in 2010 . However future $\mathrm{CO}_{2}$ emissions by transportation sector in China will further increase, with its proportion of total $\mathrm{CO}_{2}$ emissions approaching the global average and developed country levels [5].

\section{Main Features of the Transportation Sector in China}

\subsection{Increasing Energy Security Issues in Vehicles}

With the rapid growth of the car productions, sales and ownerships in China, energy security issues in vehicles are a high priority as Figure 3 shows.

After 30 years of reform and opening-up, combined with sustained and rapid growth of the economy, the vehicle ownerships have increased significantly. National civilian automobile ownership grew 57.4 times, increasing from 1.36 million in 1978 to 78.02 million in 2010, and further increasing to 109 million units in 2012, at a rate of $40.1 \%$ compared to 2010 [6].

This dramatic increase in vehicle ownership in China has resulted in the rapid growth of automobile fuel consumption, which has gradually become the main source of petroleum consumption. Presently, except for a small proportion of alternative fuel, vehicle fuel in China still consists of traditional fossil fuels, namely petroleum and diesel.

In developed countries such as European countries and the USA, the cars accounted for over $80 \%$ of the total domestic transportation energy consumption. In comparison, this proportion in China remains at a relatively lower level and is still in its infancy. However, the IEA predicts that China's proportion will reach 77\% by 2030. From 2005 to 2012, the total road traffic petroleum consumption increased from 46.1 million tons to 85.1 million tons, while the total road traffic diesel consumption increased from 54.6 million tons to 96.9 million tons [3]. 
120,000

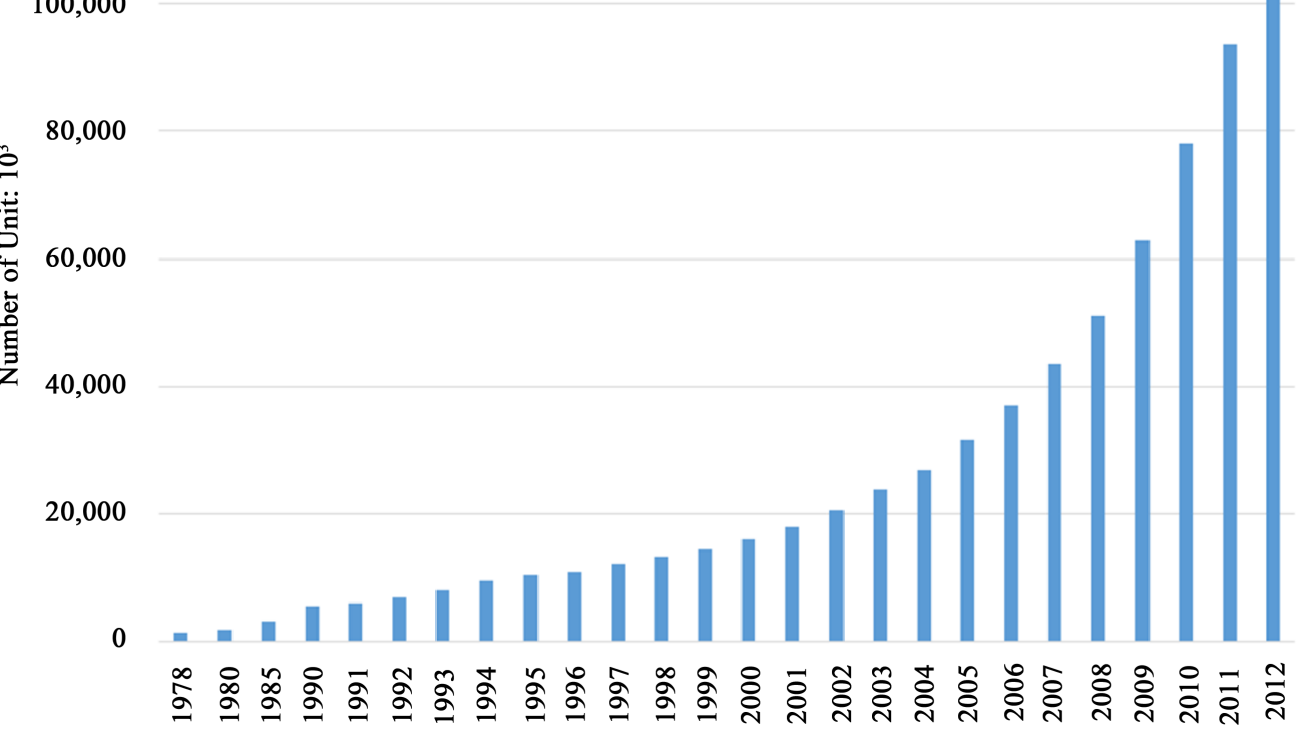

Figure 3. The number of civil motor vehicles in China (from China Statistical Yearbook 2013).

Currently, consumption reduction and alternative energy development are two ways to reduce the use of liquid petroleum products. The former is mainly to improve the fuel economy/efficiency of traditional cars, while the latter it to promote adoption of alternative fuels.

\subsection{Little Change in per Unit Transport Energy Consumption}

Fu Zhihuan et al., [7] conducted a study on the energy consumption of transportation in China. Results from this study are summarized in Table 1 and Table 2, which show the energy consumption over the past 20 years as kilogram coal equivalents (kg CE) per 1000 passenger-kilometers (PKM)and kg CE per 1000 ton-kilometers (TKM) respectively. Comparing the data, the per unit energy consumption of certain passenger transport services including civil aviation, car and taxi have reduced slightly, with no significant change in other passenger transport services. In contrast, per unit energy consumption of freight transport services has made a larger degree of progress (i.e., shows greater reduction) due to the advances in traffic technology and traffic management policies.

\section{Comparison of Study Results on the Future Outlook for Energy Consumption by Transportation Sector in China}

Reviewing existing literature, the growth trend in total energy consumption by transportation sector in China represents in China represents in Figure 4. Due to the different forecast methods and the scenarios assumptions, the future total energy consumption by transportation sector in China has a large uncertainty. Before 2030, all of the research agreed that total energy consumption by transportation sector will increase all the time, but the increasing range will around 2 or 3 times than in 2010. From 2030 to 2050, considering the different international and domestic situations, the total energy consumption by transportation sector will have bigger uncertainty than before 2030, under the strong constraint of policies the total energy consumption by transportation sector will be less than in 2030, under the strong traffic demand assumptions the total energy consumption by transportation sector will increase significant than in 2030.

\section{Conclusions and Recommendations}

China is currently in the process of rapid industrialization and urbanization. The rapidly expanding transporta- 
Table 1. Comparison of energy consumption per unit passenger transportation in China (1990, 2000, 2007) (unit: kg CE/1000 PKM).

\begin{tabular}{cccc}
\hline Mode & 1990 & 2000 & 2007 \\
\hline Highway operations & 11.7 & 11.2 & 11.4 \\
Railways & 7.3 & 7.0 & 7.2 \\
Waterways & 9.2 & 8.8 & 9.0 \\
Civil aviation & 55.6 & 51.5 & 48.6 \\
Cars & 97.4 & 81.9 & 70.6 \\
Buses & 10.0 & 9.6 & 9.8 \\
Taxis & 134 & 115 & 101 \\
\hline
\end{tabular}

Table 2. Comparison of energy consumption per unit freight transportation in China (1990, 2000, 2007) (unit: kg CE/1000 TKM).

\begin{tabular}{cccc}
\hline Mode & 1990 & 2000 & 2007 \\
\hline Highways & 74.8 & 61.3 & 54.8 \\
Railways & 11.2 & 9.8 & 8.9 \\
Waterways & 12.0 & 10.4 & 9.0 \\
Civil aviation & 550.7 & 519.6 & 485.6 \\
Pipeline & 9.1 & 8.2 & 7.5 \\
\hline
\end{tabular}

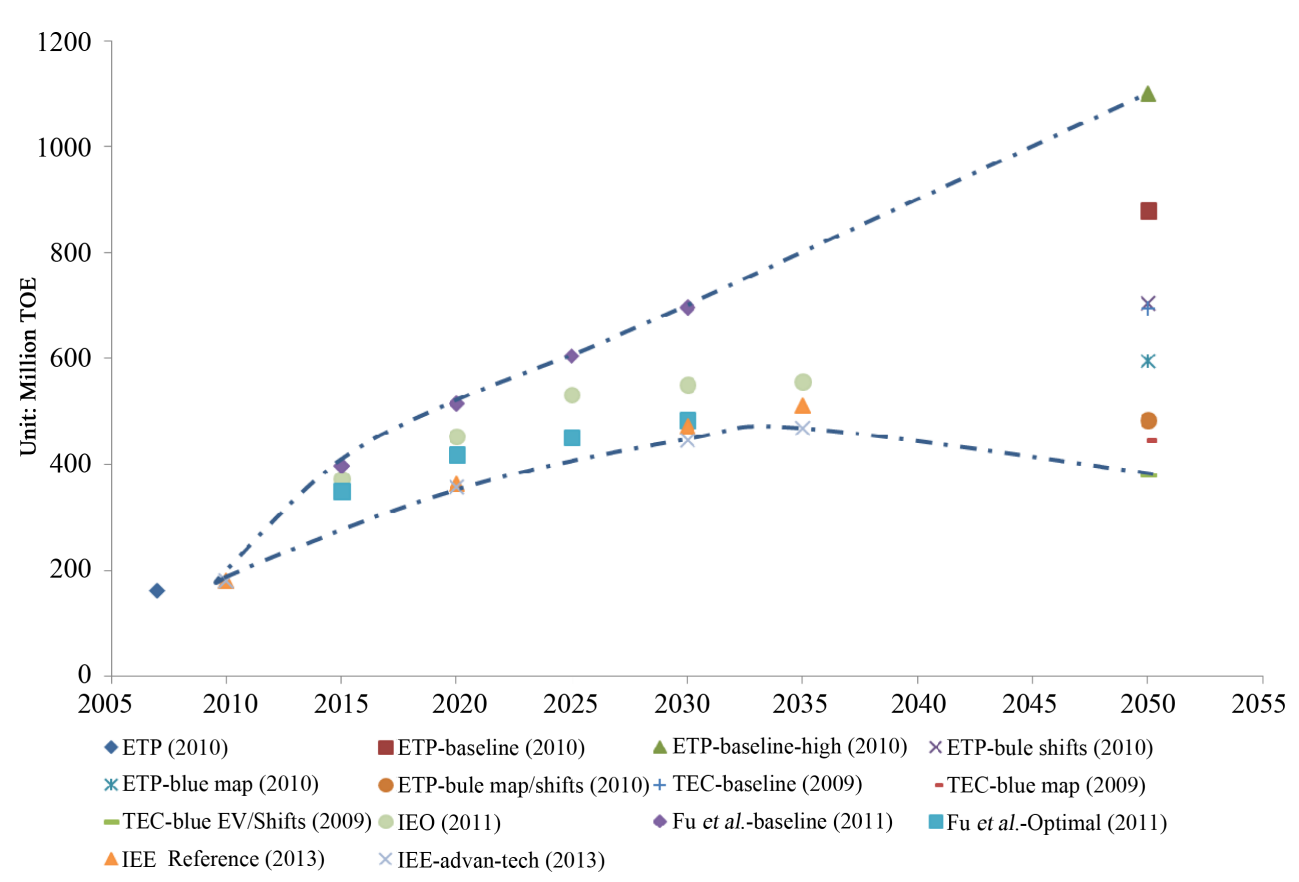

Figure 4. Summary of energy consumption forecast by transportation sector in China. Note: ETP: Energy Technology Perspectives (2010); TEC: Transport, Energy and $\mathrm{CO}_{2}$ (2009); IEO: International Energy Outlook (2011); Fu et al.: Study on problems of long-term energy saving of communication and transportation in China; IEE: The Institute of Energy Economics, Japan (EDMC 2013).

tion sector in China is facing a challenge from soaring energy consumption and greenhouse gas emissions.

The development of China's domestic transportation cannot follow the model of developed countries, especially the USA and EU, of increasing private car usage to improve people's living standards. Instead, China 
needs to further optimize traffic structure, properly allocate resources, and try to improve traffic technology and energy efficiency. This will realize the energy-saving potential on the basis of infrastructural energy saving and accelerate the developmental pace of China's low-carbon transportation sector.

\section{References}

[1] IEA (2014) Energy Technology Perspectives 2014. Inernational Energy Agency, France.

[2] EDMC (2013) Handbook of Energy \& Economic Statistics in Japan 2013. The Energy Conservation Center, Japan.

[3] Wang, Q.Y. (2013) Energy Sources Data 2013. China Automotive Energy Research Center, Beijing.

[4] IEA (2012) World Energy Outlook 2012. International Energy Agency, France.

[5] IEA (2012) $\mathrm{CO}_{2}$ Emissions from Fuel Combustion 2012. International Energy Agency, France.

[6] National Bureau of Statistics (2013) China Statistics Yearbook 2013. China Statistics Press, Beijing.

[7] Fu, Z.H., et al. (2011) Study on the Problems of Long-Term Energy Saving of Communication and Transportation in China. China Communications Press, Beijing. 
Scientific Research Publishing (SCIRP) is one of the largest Open Access journal publishers. It is currently publishing more than 200 open access, online, peer-reviewed journals covering a wide range of academic disciplines. SCIRP serves the worldwide academic communities and contributes to the progress and application of science with its publication.

Other selected journals from SCIRP are listed as below. Submit your manuscript to us via either submit@scirp.org or Online Submission Portal.
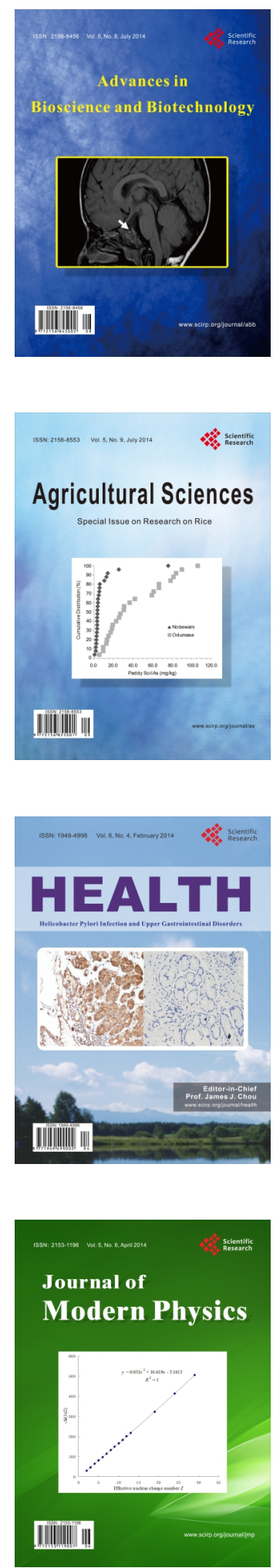
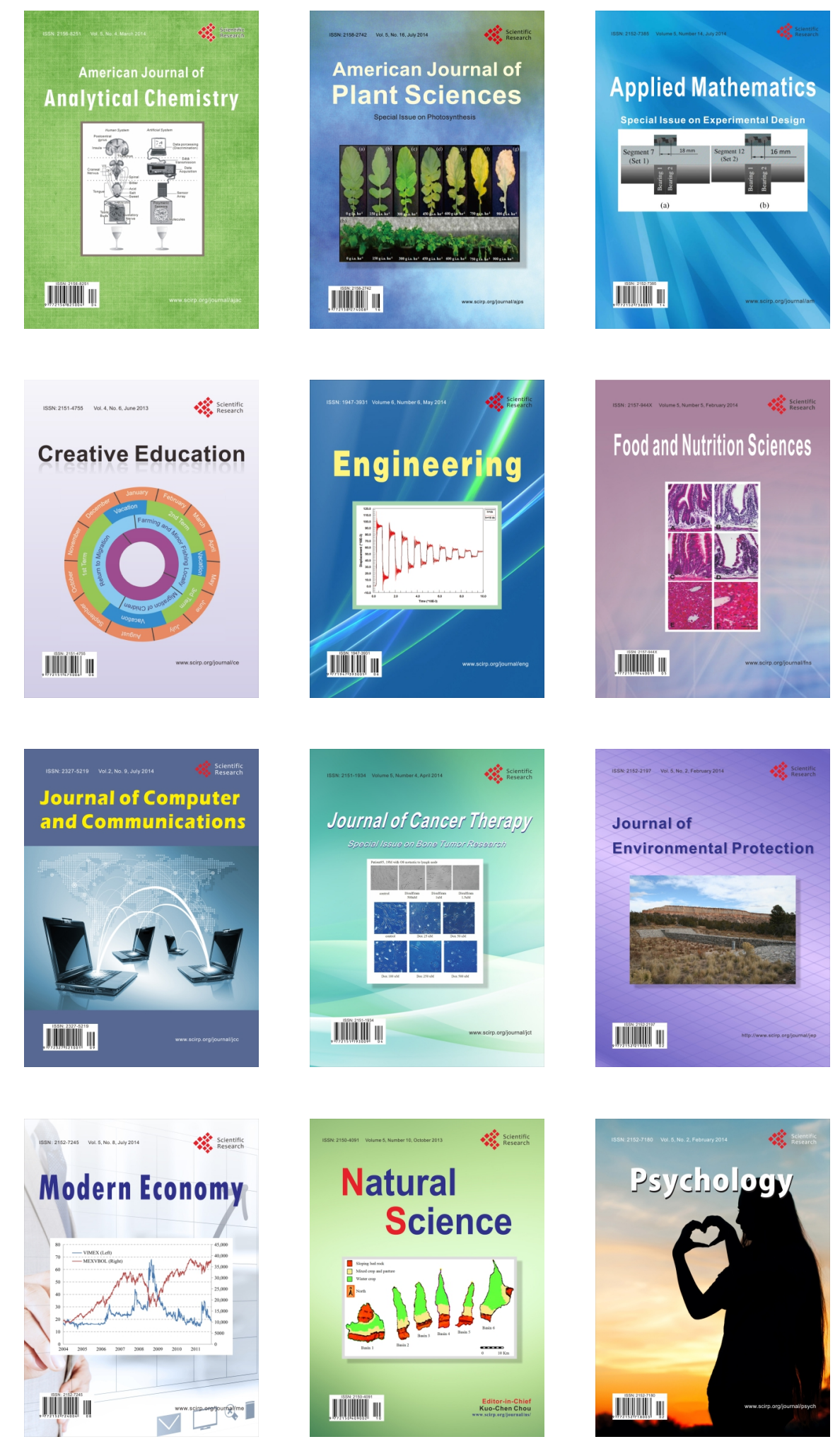